\title{
Mechanism of Enhancing Extraction of Vanadium from Stone Coal by Roasting with $\mathrm{MgO}$
}

\author{
Fang Chen ${ }^{1,2,3, *}$, Yimin Zhang ${ }^{1,2,3, *}$, Jing Huang ${ }^{1,2,3}$, Tao Liu ${ }^{1,2,3}$ and Nannan Xue ${ }^{1,2,3}$ \\ 1 College of Resource and Environment Engineering, Wuhan University of Science and Technology, \\ Wuhan 430081, China; crystal208@126.com (J.H.); tkliutao@126.com (T.L.); cbdis@aliyun.com (N.X.) \\ 2 Hubei Provincial Engineering Technology Research Center of High Efficient Cleaning Utilization for Shale \\ Vanadium Resource, Wuhan 430081, China \\ 3 Hubei Collaborative Innovation Center for High Efficient Utilization of Vanadium Resources, \\ Wuhan 430081, China \\ * Correspondence: cf126mail@126.com (F.C.); zym126135@126.com (Y.Z.); Tel.: +86-27-68862075 (F.C.)
}

Academic Editor: Saeed Chehreh Chelgani

Received: 12 January 2017; Accepted: 23 February 2017; Published: 27 February 2017

\begin{abstract}
In this paper, the extraction of vanadium from stone coal by roasting with $\mathrm{MgO}$ and leaching with sulfuric acid has been investigated, and the mechanism analysis of stone coal roasting with $\mathrm{MgO}$ was studied. The results indicated that under the conditions that the mass fraction of the particles with grain size of $0-0.074 \mathrm{~mm}$ in raw ore was $75 \%$, the roasting temperature was $500{ }^{\circ} \mathrm{C}$, the roasting time was $1 \mathrm{~h}, \mathrm{MgO}$ addition was $3 \mathrm{wt} \%$, the sulfuric acid concentration was $20 \mathrm{vol} \%$, the liquid-to-solid ratio was $1.5 \mathrm{~mL} / \mathrm{g}$, the leaching temperature was $95^{\circ} \mathrm{C}$, and leaching time was $2 \mathrm{~h}$, resulting in a vanadium leaching efficiency of $86.63 \%$, which increased by $7.73 \%$ compared with that of blank roasting. The mechanism analysis showed that the degree of calcite decomposition was low and, thus, magnesium vanadate was more easily formed than calcium vanadate below $500{ }^{\circ} \mathrm{C}$. Moreover, magnesium vanadate was easier to dissolve than calcium vanadate during the sulfuric acid leaching process. Thus, the vanadium leaching efficiency was enhanced by using $\mathrm{MgO}$ as a roasting additive below $500{ }^{\circ} \mathrm{C}$. Additionally, at high temperature the formation of tremolite would consume calcium oxide produced from the decomposition of calcite, thus, the formation of calcium vanadate was hindered, and $\mathrm{V}_{2} \mathrm{O}_{5}$ would react with $\mathrm{MgO}$ to form magnesium vanadate. Therefore, the vanadium leaching efficiency of roasting with $\mathrm{MgO}$ was higher than that of blank roasting at high temperature.
\end{abstract}

Keywords: stone coal; vanadium; $\mathrm{MgO}$; mechanism analysis

\section{Introduction}

Vanadium is an important rare metal and has been widely used in ferrous and non-ferrous alloys. Additionally, vanadium also plays a key role in some new industries, such as chemical industry, medicine, vanadium redox batteries, and so on $[1,2]$. Stone coal is a particular vanadium ore resource in China, and its gross reserves of vanadium account for more than $87 \%$ of the domestic reserves of vanadium [3-5]. Therefore, extracting vanadium from stone coal is an important way to obtain vanadium pentoxide.

In general, most of the vanadium in stone coal mainly exists as trivalent vanadium (V(III)) which substitutes for trivalent aluminum (Al(III)) in the octahedral crystal lattice of the mica minerals as an isomorphism [6-8]. The trivalent vanadium in the lattice of the mica minerals cannot be directly dissolved in acid solution, which must be oxidized to a high valence state. Thus, it is necessary to break down the crystal structure of the mica minerals for extracting vanadium from stone coal. One of the effective methods commonly used is roasting $[9,10]$. 
Many roasting methods in the vanadium extraction process of low grade vanadium-bearing stone coal have been proposed in the past. Traditionally, the most widely-applied roasting method is sodium roasting. However, sodium roasting produces corrosive gases, including $\mathrm{HCl}, \mathrm{Cl}_{2}, \mathrm{SO}_{2}$, and $\mathrm{SO}_{3}$, which corrode equipment severely and contaminate the environment [11-14]. These serious disadvantages have limited further development of this roasting method, which has been prohibited by the government in recent years and replaced by some modified roasting methods, such as calcified roasting, oxidizing roasting, and composite additives roasting. Though the exhaust gas pollution is avoided in calcified roasting, the roasting method has high energy consumption and a strong selectivity for minerals, thereby the application of calcified roasting method is limited $[15,16]$. The oxidizing roasting method can greatly reduce gas pollution, but the leaching efficiency of vanadium is low [17-19]. The composite additives roasting method can decrease the amount of poisonous gas discharge and has a high leaching efficiency of vanadium. However, the method lacks the general applicability of vanadium-bearing minerals [20,21]. Generally speaking, these roasting methods have various problems, such as low vanadium leaching efficiency, high production cost, environmental pollution, and so on. Owing to the increasing environmental concerns, it is essential to research and develop an environmentally-friendly technology with higher recovery of vanadium for extracting vanadium from stone coal.

The aim of this work is to enhance the extraction of vanadium from stone coal by using $\mathrm{MgO}$ as roasting additive, which had good function of sulfur fixation and could reduce the release of pollution. This work has certain referential significance for the selection of the additives in the roasting process for extracting vanadium from stone coal.

\section{Experimental}

\subsection{Materials}

The stone coal used in this work was obtained from Jiangxi Province, China. The ore was crushed and ground to a certain particle size. The obtained ore was referred to as raw ore throughout this work. All of the reagents used were of analytical reagent grade. The particle size of $\mathrm{MgO}$ used is $\sim 0.074 \mathrm{~mm}$. All of the water used in this work was distilled water.

The chemical composition of the raw ore was analyzed through ICP-AES (Inductively Coupled Plasma-Atomic Emission Spectroscopy) method and the result was given in Table 1. As shown in Table 1 , the content of vanadium in terms of $\mathrm{V}_{2} \mathrm{O}_{5}$ was $0.80 \%$ and $\mathrm{SiO}_{2}$ was the main composition. The mineralogical composition of the raw ore was identified by X-ray diffraction (XRD, Rigaku, Tokyo, Japan) analysis (Figure 1). The electron probe micro-analysis (EPMA) of the raw ore was performed and the result was shown in Table 2. Combined Figure 1 and Table 2, it could be seen that the raw ore was mainly composed of quartz, muscovite, and calcite. Moreover, muscovite was the main vanadium-bearing mineral. Table 3 showed vanadium phase analysis and its valence state in raw ore. It indicated that vanadium mainly existed in silicoaluminate minerals (namely mica minerals) in the form of $\mathrm{V}(\mathrm{III})$.

Table 1. Chemical compositions of the raw ore wt $\%$.

\begin{tabular}{lcccccccccc}
\hline Element & $\mathbf{V}_{\mathbf{2}} \mathrm{O}_{\mathbf{5}}$ & $\mathrm{SiO}_{2}$ & $\mathrm{Al}_{2} \mathrm{O}_{3}$ & $\mathrm{Fe}_{2} \mathbf{O}_{3}$ & $\mathbf{C a O}$ & $\mathbf{M g O}$ & $\mathbf{K}_{2} \mathbf{O}$ & $\mathbf{N a}_{2} \mathbf{O}$ & $\mathbf{C}$ & $\mathbf{S}$ \\
\hline Content & 0.80 & 65.00 & 6.78 & 3.75 & 3.29 & 1.53 & 1.73 & 0.58 & 9.21 & 0.87 \\
\hline
\end{tabular}

Table 2. EPMA result of the raw ore wt \%.

\begin{tabular}{ccccccccc}
\hline Minerals & V & Si & Al & Fe & Ca & Mg & K & O \\
\hline Quartz & 0.00 & 42.91 & 0.03 & 0.00 & 0.00 & 0.00 & 0.00 & 49.07 \\
Muscovite & 0.97 & 26.57 & 3.66 & 0.35 & 0.03 & 0.67 & 1.71 & 35.06 \\
Calcite & 0.01 & 0.71 & 0.31 & 0.00 & 38.53 & 0.32 & 0.25 & 16.81 \\
\hline
\end{tabular}


Table 3. Vanadium phase analyses and its valence state in raw ore wt $\%$.

\begin{tabular}{lccccccc}
\hline \multirow{2}{*}{ Category } & $\begin{array}{c}\text { Total } \\
\text { Vanadium }\end{array}$ & $\begin{array}{c}\text { Bound to } \\
\text { Free Oxide }\end{array}$ & Silicoaluminate & $\begin{array}{c}\text { Bound to } \\
\text { Organics }\end{array}$ & V(III) & V(IV) & V(V) \\
\hline Percentage & 100 & 7 & 89 & 4 & 73 & 27 & 0 \\
\hline
\end{tabular}

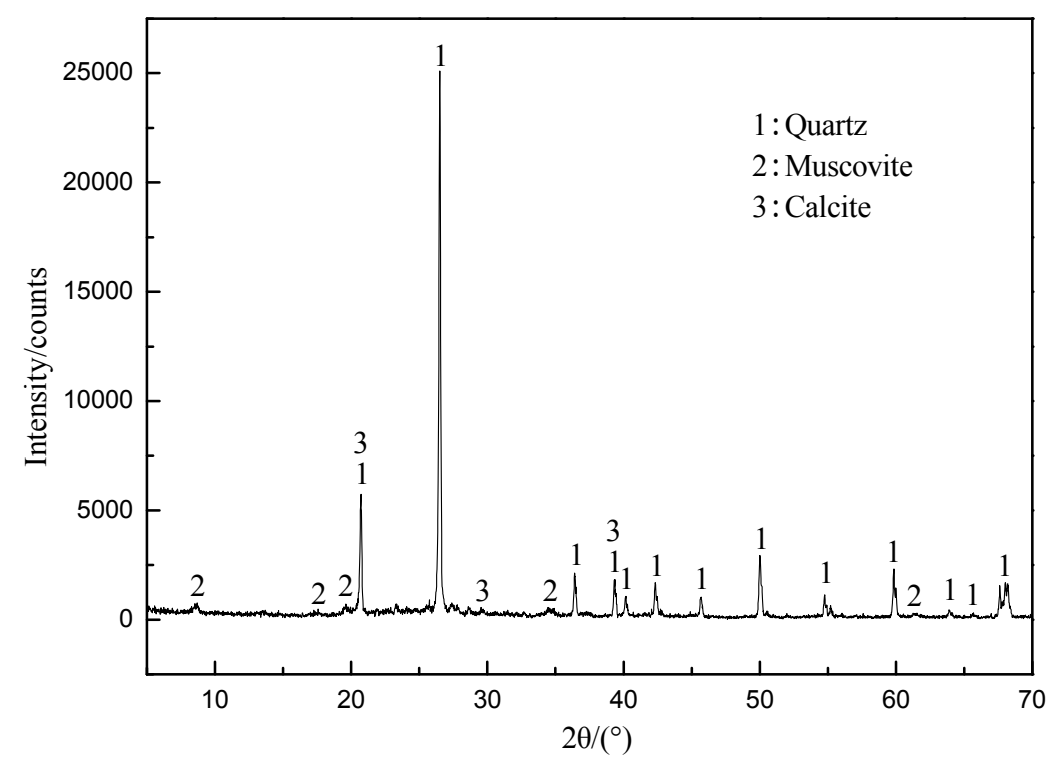

Figure 1. XRD pattern of the raw ore.

\subsection{Procedure and Methods}

Every experiment adopted forty grams raw ore. The sample, which was composed of the raw ore and a certain amount of magnesium oxide, was put in a crucible and heated in a muffle furnace for a certain period of time. During the roasting process the door of the muffle furnace was kept open to maintain an oxidizing atmosphere.

The leaching experiments were performed at an atmospheric pressure in a magnetic stirrer capable of heating and stirring. In all the leaching experiments, the roasted sample was leaching in $20 \mathrm{vol} \%$ sulfuric acid solution according to the liquid-to-solid ratio of $1.5 \mathrm{~mL} / \mathrm{g}$ at temperature of $95^{\circ} \mathrm{C}$ for $2 \mathrm{~h}$. The liquid-to-solid ratio referred to the ratio of the sulfuric acid solution volume $(\mathrm{mL})$ and raw ore quality (g), which meant that the volume of sulfuric acid solution was kept constant at $60 \mathrm{~mL}$ during the leaching process. At the end of each leaching test, the leaching slurry was filtered by vacuum filtration and the leaching solution and leaching residue were obtained. The amount of vanadium pentoxide in the leaching solution was determined by ferrous ammonium sulfate titration method [22].

The chemical composition of the raw ore was determined by ICP-AES performed on the IRIS Advantage ER/S instrument (Thermo Elemental, Boston, MA, USA).

X-ray diffraction (XRD) patterns were obtained by using a Rigaku D/MAX-RB X-ray diffraction (Rigaku, Tokyo, Japan) with $\mathrm{Cu} \mathrm{K} \alpha$ radiation.

A JAX-8230 electronic probe micro-analyzer (EPMA) was applied for quantitative elementary analysis and mineralogical composition.

Microscopic observation and elemental analysis (SEM with EDS) was conducted by using a JEOL JSM-6610 scanning electronic microscope (JEOL, Tokyo, Japan) equipped with a BRUKER QUANTAX200-30 energy dispersive spectrometer (BRUKER, Karlsruhe, Germany).

The apparent density was determined by using a SK-1002 loose density tester (Qunlong, Xiamen, China). 


\section{Results and Discussion}

\subsection{Effect of Roasting Temperature on Vanadium Leaching Efficiency}

The effect of roasting temperature from 400 to $900{ }^{\circ} \mathrm{C}$ on vanadium leaching efficiency was investigated under the conditions that $\mathrm{MgO}$ addition was 0 or $3 \mathrm{wt} \%$ and roasting time was $1 \mathrm{~h}$. The mass fraction of the particles with grain size of $0-0.074 \mathrm{~mm}$ in raw ore was $75 \%$. The result was presented in Figure 2.

As illustrated in Figure 2, roasting temperature had a significant effect on vanadium leaching efficiency. The vanadium leaching efficiency reached the maximum value (namely $86.63 \%$ ) at around $500{ }^{\circ} \mathrm{C}$. The vanadium leaching efficiency decreased when the roasting temperature was below or above $500^{\circ} \mathrm{C}$. In particular, the vanadium leaching efficiency of blank roasting decreased obviously after $800^{\circ} \mathrm{C}$. However, the vanadium leaching efficiency of roasting with $\mathrm{MgO}$ decreased obviously after $900{ }^{\circ} \mathrm{C}$. It could also be seen from Figure 2 that under the same roasting temperature the vanadium leaching efficiency could be improved by adding $\mathrm{MgO}$ in the roasting process. Furthermore, the difference of vanadium leaching efficiency between roasting with $\mathrm{MgO}$ and blank roasting was more obvious at high temperature. Therefore, the optimum roasting temperature should be $500{ }^{\circ} \mathrm{C}$.

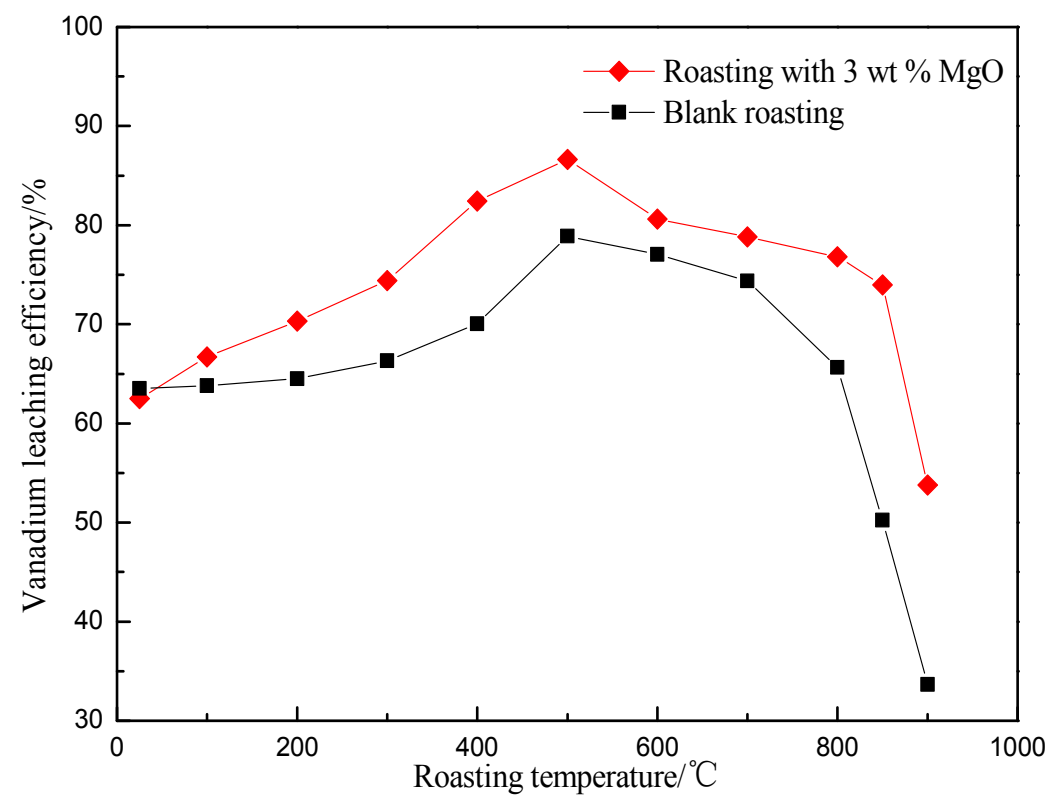

Figure 2. Effect of roasting temperature on vanadium leaching efficiency.

\subsection{Effect of Roasting Time on Vanadium Leaching Efficiency}

The effect of roasting time from 0.5 to $2 \mathrm{~h}$ on vanadium leaching efficiency was studied under the conditions that $\mathrm{MgO}$ addition was 0 or $3 \mathrm{wt} \%$ and roasting temperature was $500{ }^{\circ} \mathrm{C}$. The mass fraction of the particles with grain size of $0-0.074 \mathrm{~mm}$ in raw ore was $75 \%$. The result was illustrated in Figure 3.

The vanadium leaching efficiency without roasting process was only $62.52 \%$. It could be observed that roasting time had influence on vanadium leaching efficiency. The vanadium leaching efficiency increased with the rise of roasting time. While the roasting time is short, the transformation of vanadium from low valence to high valence was not complete. However, when roasting time was above $1 \mathrm{~h}$, the vanadium leaching efficiency remained unchanged, which might be due to the fact that the oxidation reaction of vanadium reached equilibrium. Figure 3 also showed that under the same roasting time the vanadium leaching efficiency could be improved by roasting with $\mathrm{MgO}$. Thus, roasting time of $1 \mathrm{~h}$ was found to be optimum for roasting process. 


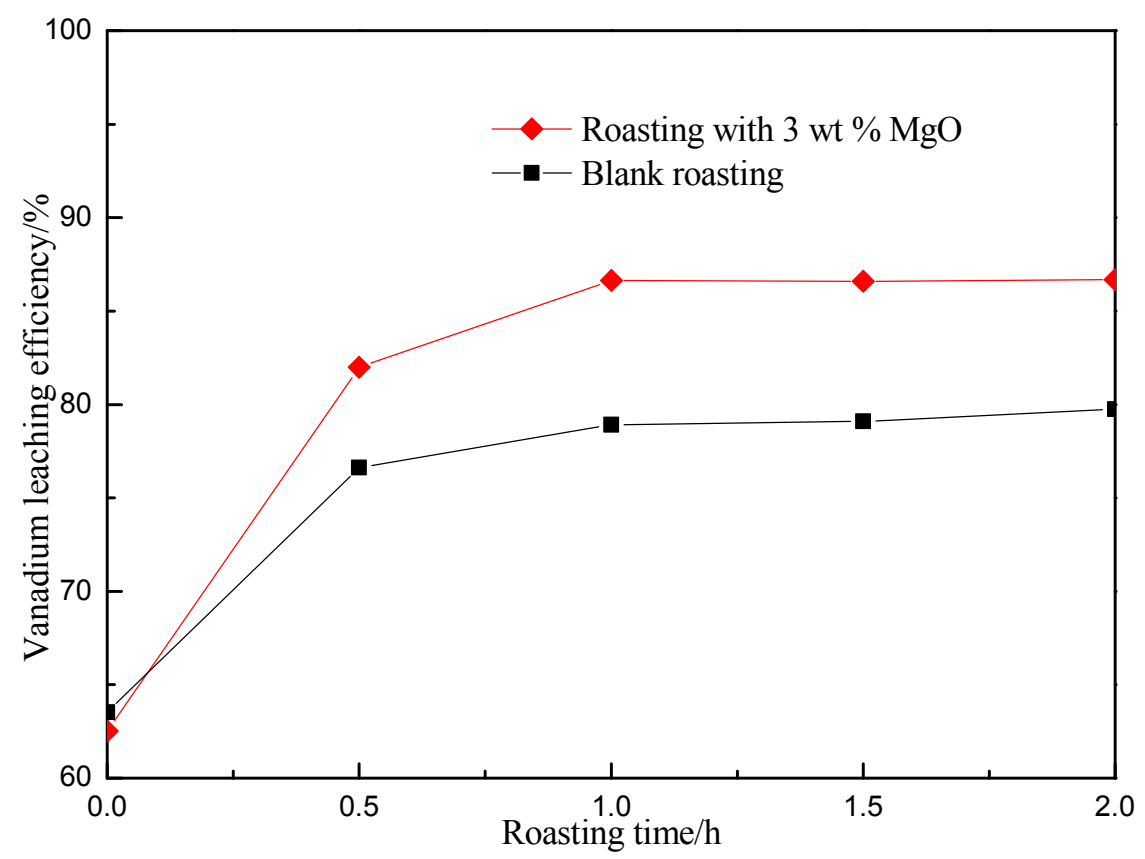

Figure 3. Effect of roasting time on vanadium leaching efficiency.

\subsection{Effect of $\mathrm{MgO}$ Dosage on Vanadium Leaching Efficiency}

The effect of $\mathrm{MgO}$ dosage on vanadium leaching efficiency was investigated under the conditions that roasting temperature was $500{ }^{\circ} \mathrm{C}$ and roasting time was $1 \mathrm{~h}$. The mass fraction of the particles with grain size of $0-0.074 \mathrm{~mm}$ in raw ore was $75 \%$. The result was shown in Figure 4 .

The vanadium leaching efficiency of blank roasting was $78.90 \%$. Figure 4 indicated that the vanadium leaching efficiency increased significantly with the increase of $\mathrm{MgO}$ dosage. Nevertheless, while $\mathrm{MgO}$ dosage exceeded $3 \mathrm{wt} \%$, the increase of vanadium leaching efficiency was not obvious. Hence, $\mathrm{MgO}$ dosage of $3 \mathrm{wt} \%$ was chosen as the optimal condition for roasting process.

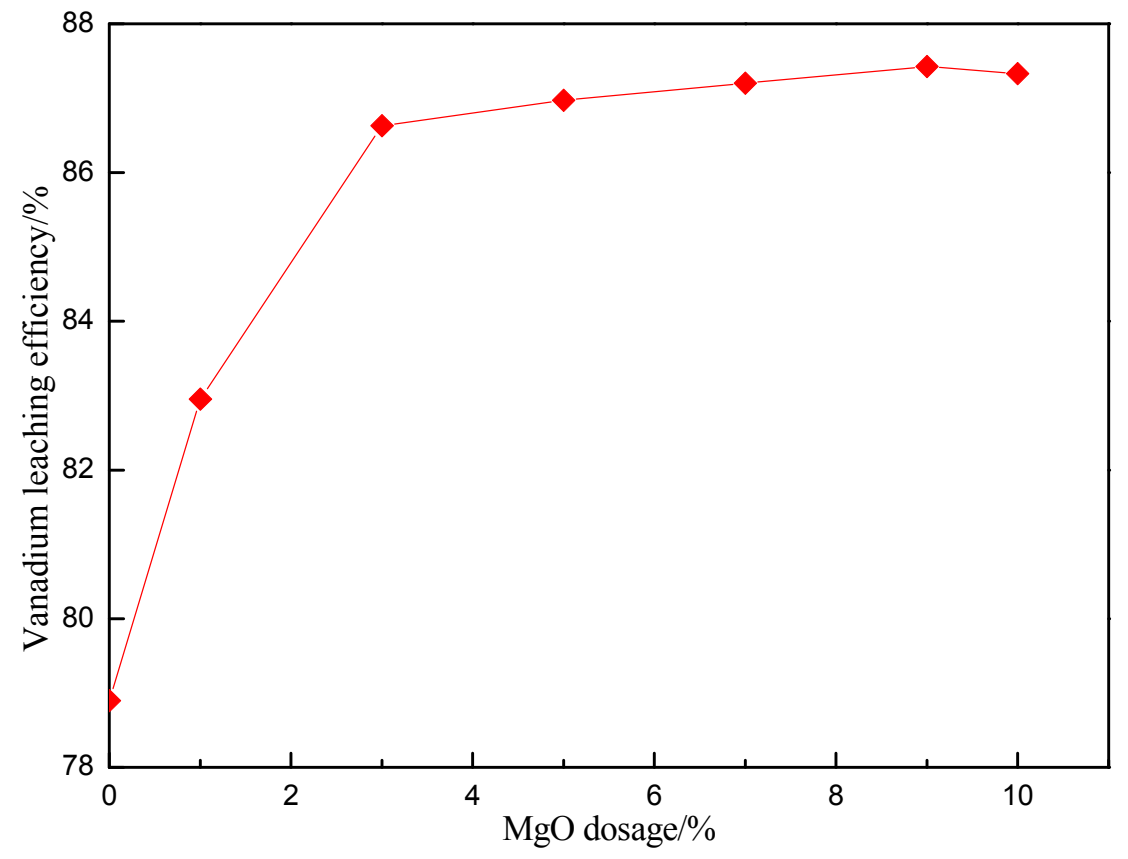

Figure 4. Effect of $\mathrm{MgO}$ dosage on vanadium leaching efficiency. 


\subsection{Effect of the Particle Size of Raw Ore on Vanadium Leaching Efficiency}

The effect of the particle size of raw ore on vanadium leaching efficiency was investigated under the conditions that roasting temperature was $500{ }^{\circ} \mathrm{C}, \mathrm{MgO}$ addition was $3 \mathrm{wt} \%$ and roasting time was $1 \mathrm{~h}$. The result was shown in Figure 5.

As shown in Figure 5, the vanadium leaching efficiency increased with the decrease of the particle size of raw ore. While the mass fraction of the particles with the grain size of $0-0.074 \mathrm{~mm}$ exceeded $75 \%$, the vanadium leaching efficiency began to decline. The reason might be that the viscosity of leaching slurry increased when the particle size of raw ore was too small, which hindered the leaching process. Thus, the mass fraction of the particles with the grain size of $0-0.074 \mathrm{~mm}$ in raw ore should be $75 \%$.

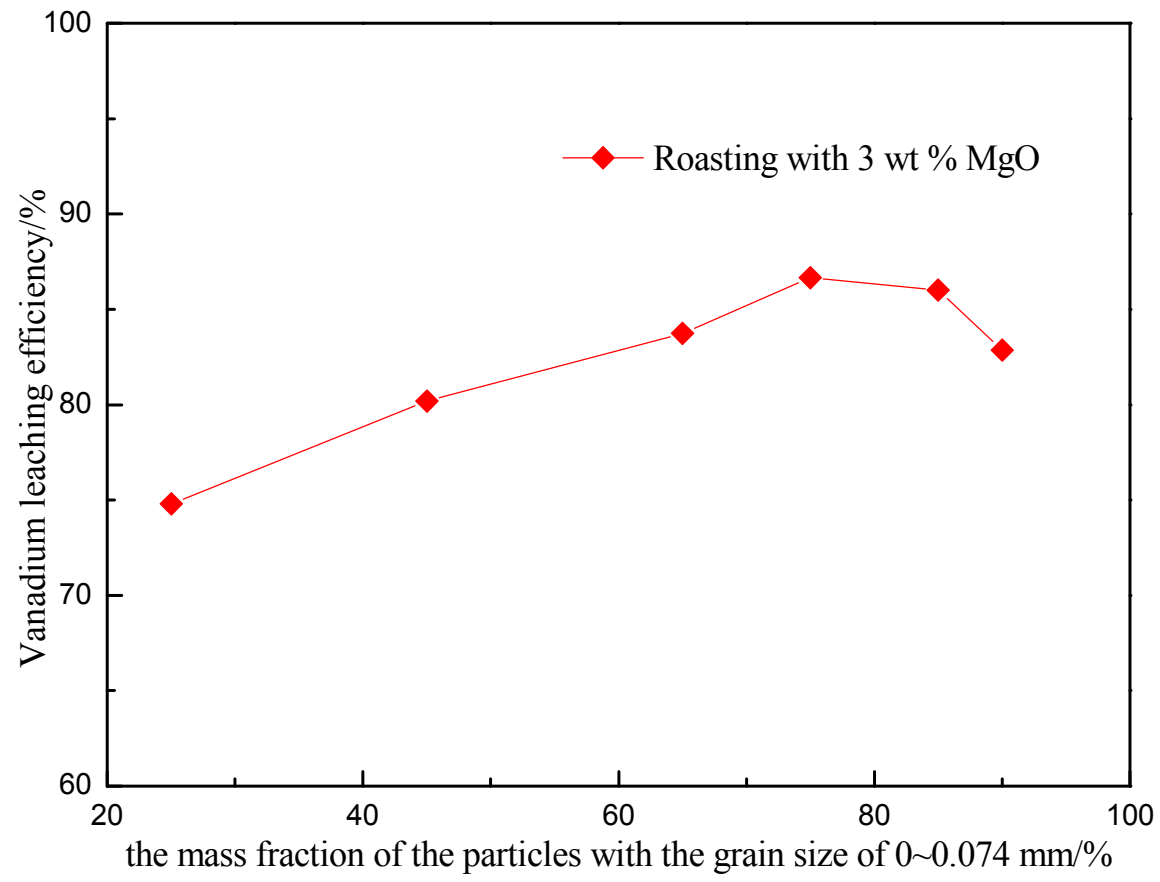

Figure 5. Effect of the particle size of raw ore on vanadium leaching efficiency.

\subsection{The Mechanism Analysis of Stone Coal Roasting with $\mathrm{MgO}$}

The phase transformation of the samples roasted with $3 \mathrm{wt} \% \mathrm{MgO}$ at different roasting temperatures for $1 \mathrm{~h}$ were analyzed by XRD. The XRD patterns were presented in Figure 6.

It could be seen that the diffraction peaks of calcite could not be identified when the roasting temperature increased to $700{ }^{\circ} \mathrm{C}$. Meanwhile, the diffraction peaks of muscovite were weakened with the increase of roasting temperature and then disappeared at $900{ }^{\circ} \mathrm{C}$, indicating that during the roasting process the structure of muscovite was destroyed, and then the vanadium in the octahedron crystal lattice of muscovite could be released and oxidized into high valence vanadium. Hence, below $500{ }^{\circ} \mathrm{C}$ the vanadium leaching efficiency was improved with the increase of roasting temperature.

It could also be observed from Figure 6 that two new mineral phases, sanidine and tremolite, appeared at $900{ }^{\circ} \mathrm{C}$. To confirm the existence of tremolite, the SEM image and corresponding EDS analysis of the sample roasted with $3 \mathrm{wt} \% \mathrm{MgO}$ at $900{ }^{\circ} \mathrm{C}$ for $1 \mathrm{~h}$ were conducted. The results were shown in Figure 7.

Figure 7 revealed that the elemental distribution of $\mathrm{O}, \mathrm{Mg}, \mathrm{Si}$, and $\mathrm{Ca}$ had obvious relevance. Combined with the XRD patterns of the roasted samples in Figure 6, the tremolite, which had good thermal stability, existed in the sample roasted with $3 \mathrm{wt} \% \mathrm{MgO}$ at $900{ }^{\circ} \mathrm{C}$ for $1 \mathrm{~h}$. 


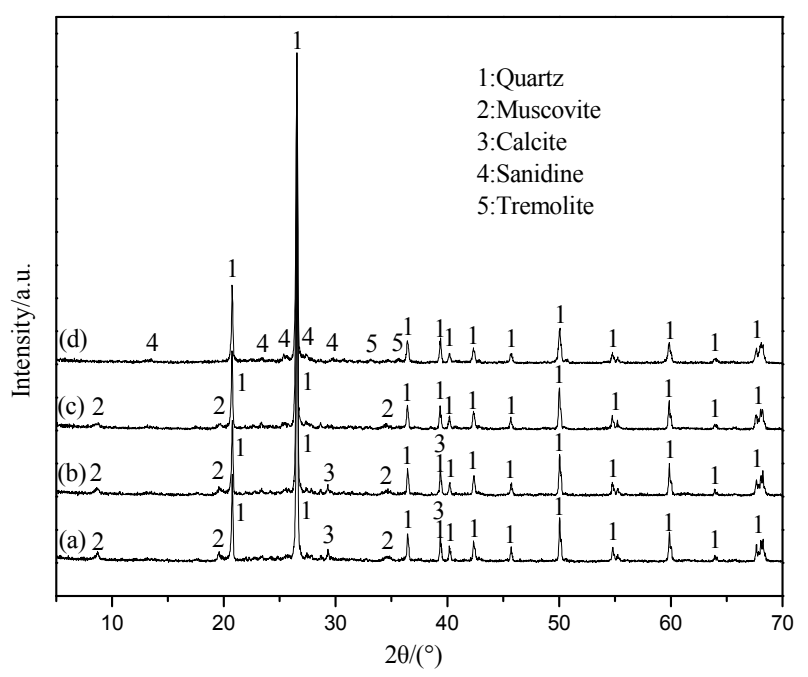

Figure 6. XRD patterns of the samples roasted with $3 \mathrm{wt} \% \mathrm{MgO}$ at different roasting temperatures for 1 h. (a) $400{ }^{\circ} \mathrm{C}$; (b) $500{ }^{\circ} \mathrm{C}$; (c) $700{ }^{\circ} \mathrm{C}$; and (d) $900{ }^{\circ} \mathrm{C}$.
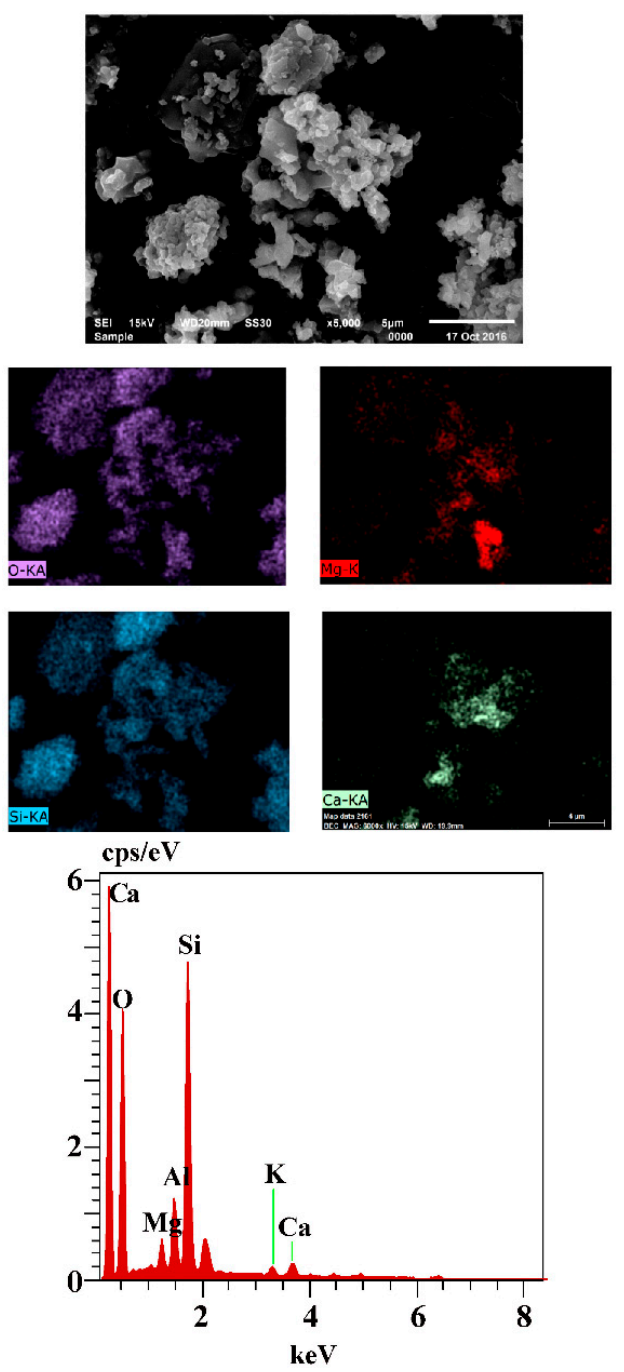

Figure 7. SEM image and corresponding EDS analysis of the sample roasted with $3 \mathrm{wt} \% \mathrm{MgO}$ at $900{ }^{\circ} \mathrm{C}$ for $1 \mathrm{~h}$. 
To find out the reason why vanadium leaching efficiency decreased at high temperature, the SEM images of the roasted samples at $850{ }^{\circ} \mathrm{C}$ were observed.

As shown in Figure 8a, some particles were bonded to each other and then big molten mass formed after roasting at $850{ }^{\circ} \mathrm{C}$, which indicated that the sample was sintered at $850{ }^{\circ} \mathrm{C}$ [23]. A similar situation could also be observed in Figure $8 \mathrm{~b}$. Hence, it was reasonable to deduce that the decrease of vanadium leaching efficiency at high temperature might be attributed to that the samples were sintered.
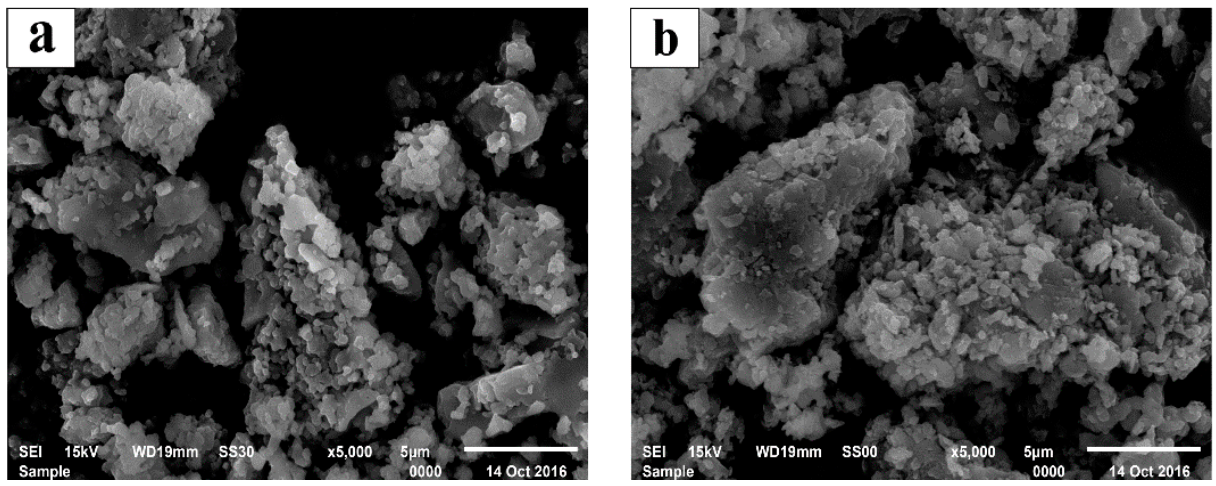

Figure 8. SEM images of the roasted samples at $850{ }^{\circ} \mathrm{C}$ : (a) Blank roasting; (b) Roasting with 3 wt \% MgO.

To confirm the deduction that the decrease of vanadium leaching efficiency at high temperature was due to the face that the samples were sintered. The apparent density of the roasted samples at different roasting temperatures was determined and the results are presented in Figure 9.

It was demonstrated that, before $900^{\circ} \mathrm{C}$, the apparent density increased slightly with the increase of roasting temperature, which was due to the slight sintering of the samples. After $900{ }^{\circ} \mathrm{C}$ the apparent density increased sharply. This suggested that the samples were sintered seriously [24]. At this time some vanadium in the raw ore might be enwrapped in the formed sintered sample, which was hard to be leached by sulfuric acid. Thus, the vanadium leaching efficiency decreased at high temperature. Meanwhile, it could be seen that under the same conditions the apparent density of the sample roasted with $3 \mathrm{wt} \% \mathrm{MgO}$ was less than that of the blank roasted sample.

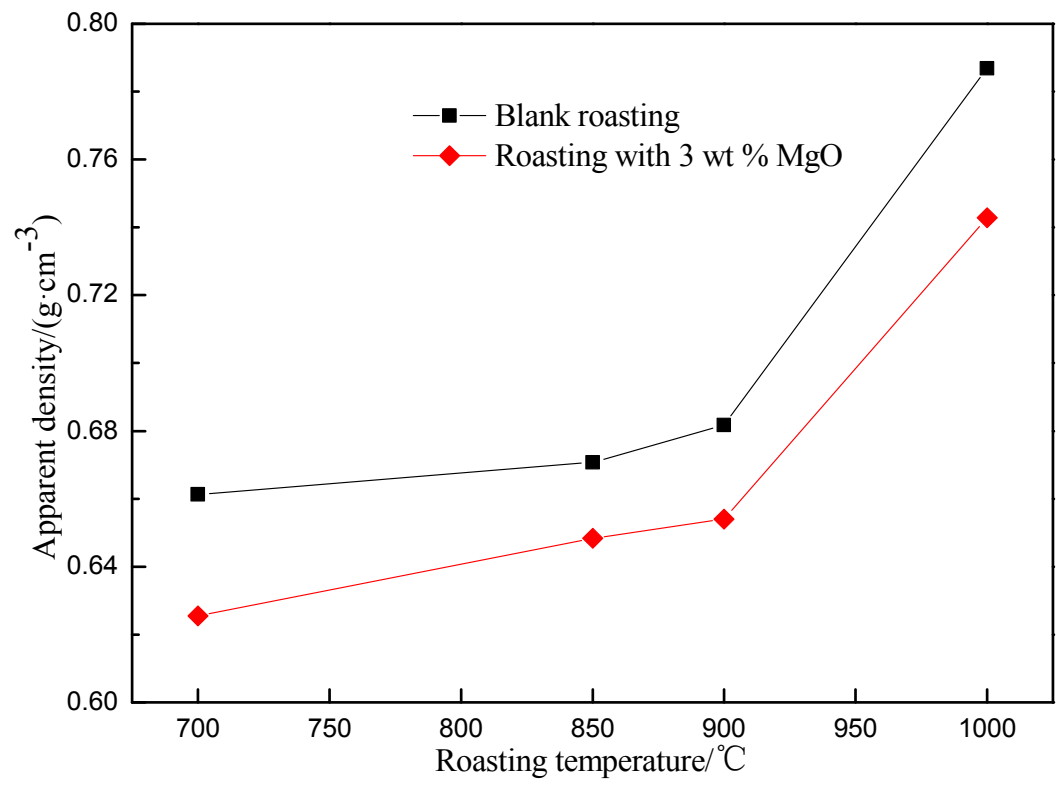

Figure 9. Apparent density of the roasted samples at different roasting temperatures. 
To study the function of $\mathrm{MgO}$ on vanadium extraction from stone coal, the SEM images and corresponding EDS analysis of the blank roasted sample and the sample roasted with $3 \mathrm{wt} \% \mathrm{MgO}$ at $500{ }^{\circ} \mathrm{C}$ were conducted.

Researchers had proposed that vanadate compounds appeared during the stone coal roasting process [25]. The relevance of $\mathrm{V}, \mathrm{Ca}$, and $\mathrm{O}$ shown in Figure 10a indicated that the vanadium in the blank roasted sample at $500{ }^{\circ} \mathrm{C}$ was probably in the form of calcium vanadate, which was difficult to be leached by the sulfuric acid. Nevertheless, Figure 10b illustrated that the elemental distribution of $\mathrm{V}, \mathrm{Mg}$, and $\mathrm{O}$ had obvious relevance. Combined with [26,27], it could be deduced that magnesium vanadate existed in the sample roasted with $3 \mathrm{wt} \% \mathrm{MgO}$ at $500{ }^{\circ} \mathrm{C}$. Moreover, magnesium vanadate was easier to dissolve than calcium vanadate during the sulfuric acid leaching process $[28,29]$. Therefore, it may be due to the formation of magnesium vanadate that the vanadium leaching efficiency of roasting with $\mathrm{MgO}$ was higher than that of blank roasting.
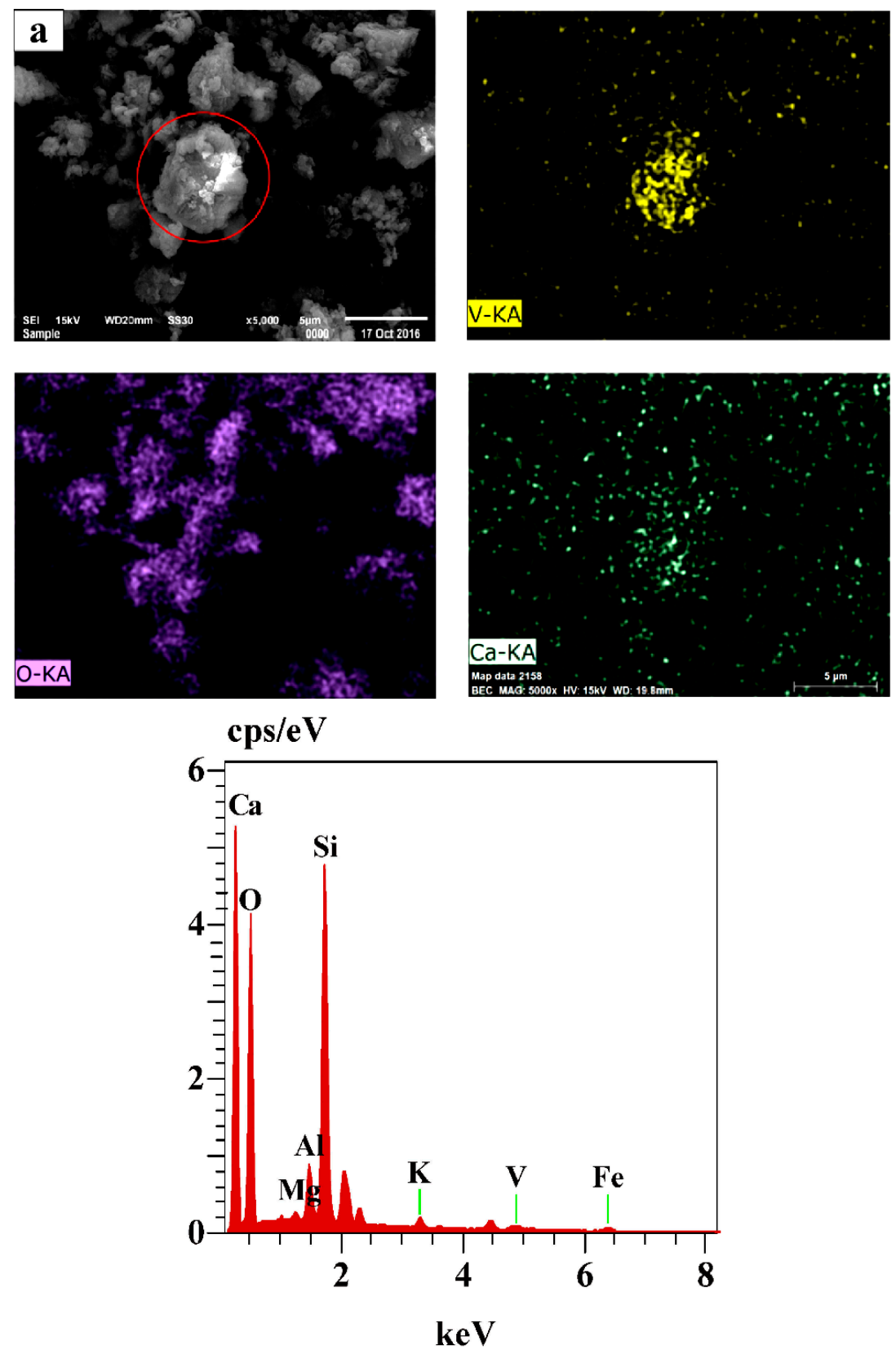

Figure 10. Cont. 


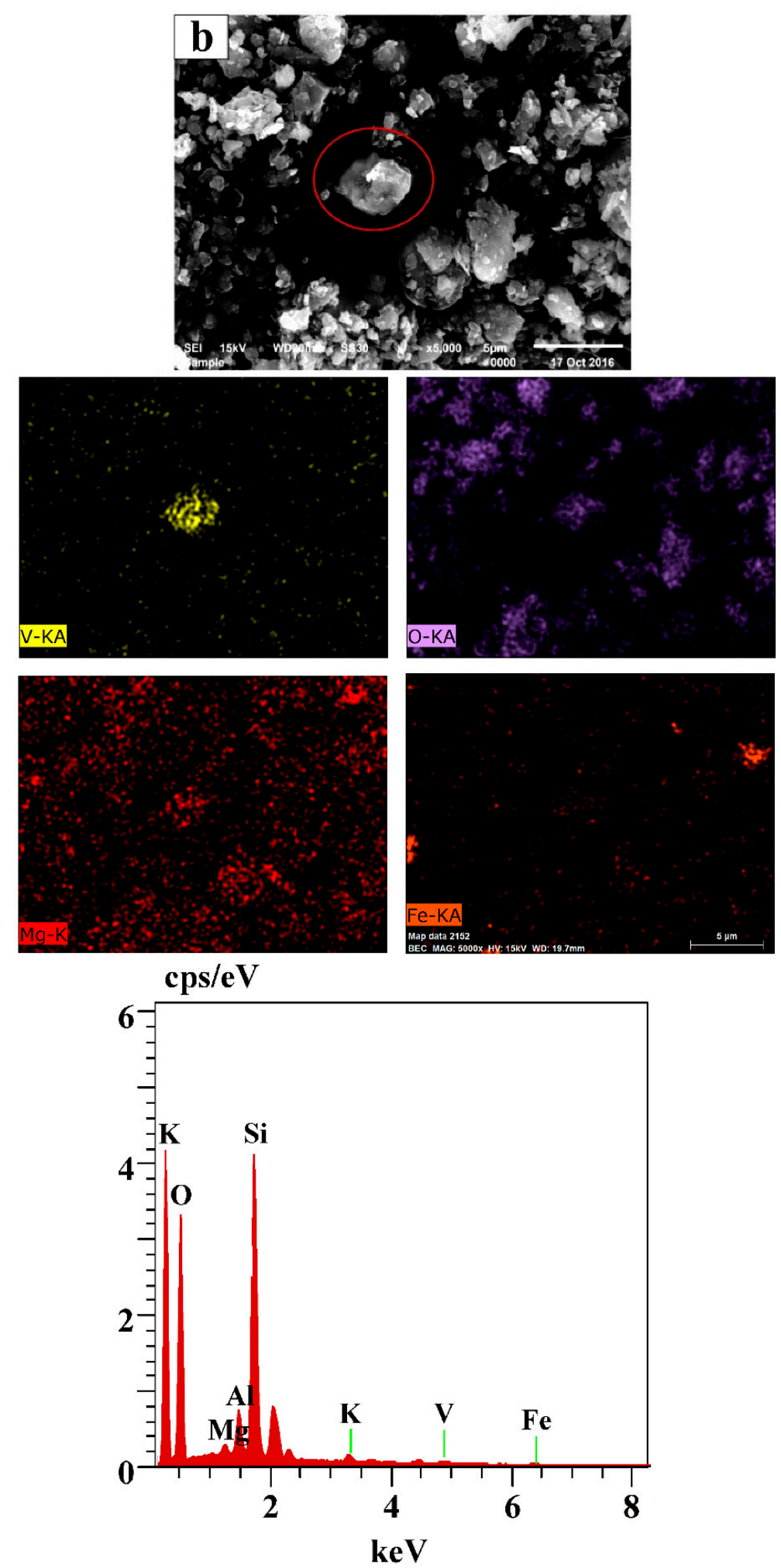

Figure 10. SEM images and corresponding EDS analysis of the blank roasted sample (a) and the sample roasted with 3 wt $\% \mathrm{MgO}\left(\right.$ b) at $500{ }^{\circ} \mathrm{C}$.

From the above experiments and analysis, it could be concluded that the stone coal roasting process was a complex chemical reaction process. The main chemical reactions that occurred during stone coal roasting process were shown in Table 4. HSC Chemistry software (Outokumpu Research OY, 
Pori, Finland) was designed for various kinds of chemical reactions and equilibria calculations [30-32]. The standard Gibbs free energy changes $\Delta G^{\Theta}$ for each reaction at different temperatures could be obtained by HSC Chemistry software. The results are shown in Figure 11.

Table 4. The main chemical reactions during stone coal roasting process.

\begin{tabular}{cc}
\hline No. & Chemical Reactions \\
\hline$(1)$ & $\mathrm{V}_{2} \mathrm{O}_{3}+\mathrm{O}_{2}=\mathrm{V}_{2} \mathrm{O}_{5}$ \\
$(2)$ & $2 \mathrm{~V}_{2} \mathrm{O}_{4}+\mathrm{O}_{2}=2 \mathrm{~V}_{2} \mathrm{O}_{5}$ \\
$(3)$ & $\mathrm{MgO}+\mathrm{V}_{2} \mathrm{O}_{5}=\mathrm{MgV}_{2} \mathrm{O}_{6}$ \\
$(4)$ & $2 \mathrm{MgO}+\mathrm{V}_{2} \mathrm{O}_{5}=\mathrm{Mg}_{2} \mathrm{~V}_{2} \mathrm{O}_{7}$ \\
$(5)$ & $3 \mathrm{MgO}+\mathrm{V}_{2} \mathrm{O}_{5}=\mathrm{Mg}_{3}\left(\mathrm{VO}_{4}\right)_{2}$ \\
$(6)$ & $\mathrm{CaO}+\mathrm{V}_{2} \mathrm{O}_{5}=\mathrm{CaV}_{2} \mathrm{O}_{6}$ \\
$(7)$ & $2 \mathrm{CaO}+\mathrm{V}_{2} \mathrm{O}_{5}=\mathrm{Ca}_{2} \mathrm{~V}_{2} \mathrm{O}_{7}$ \\
$(8)$ & $3 \mathrm{CaO}+\mathrm{V}_{2} \mathrm{O}_{5}=\mathrm{Ca}_{3} \mathrm{~V}_{2} \mathrm{O}_{8}$ \\
$(9)$ & $2 \mathrm{CaO}+5 \mathrm{MgO}+8 \mathrm{SiO} \mathrm{O}_{2}+\mathrm{H}_{2} \mathrm{O}=\mathrm{Ca}_{2} \mathrm{Mg}_{5} \mathrm{Si}_{8} \mathrm{O}_{22}(\mathrm{OH})_{2}$ \\
\hline
\end{tabular}

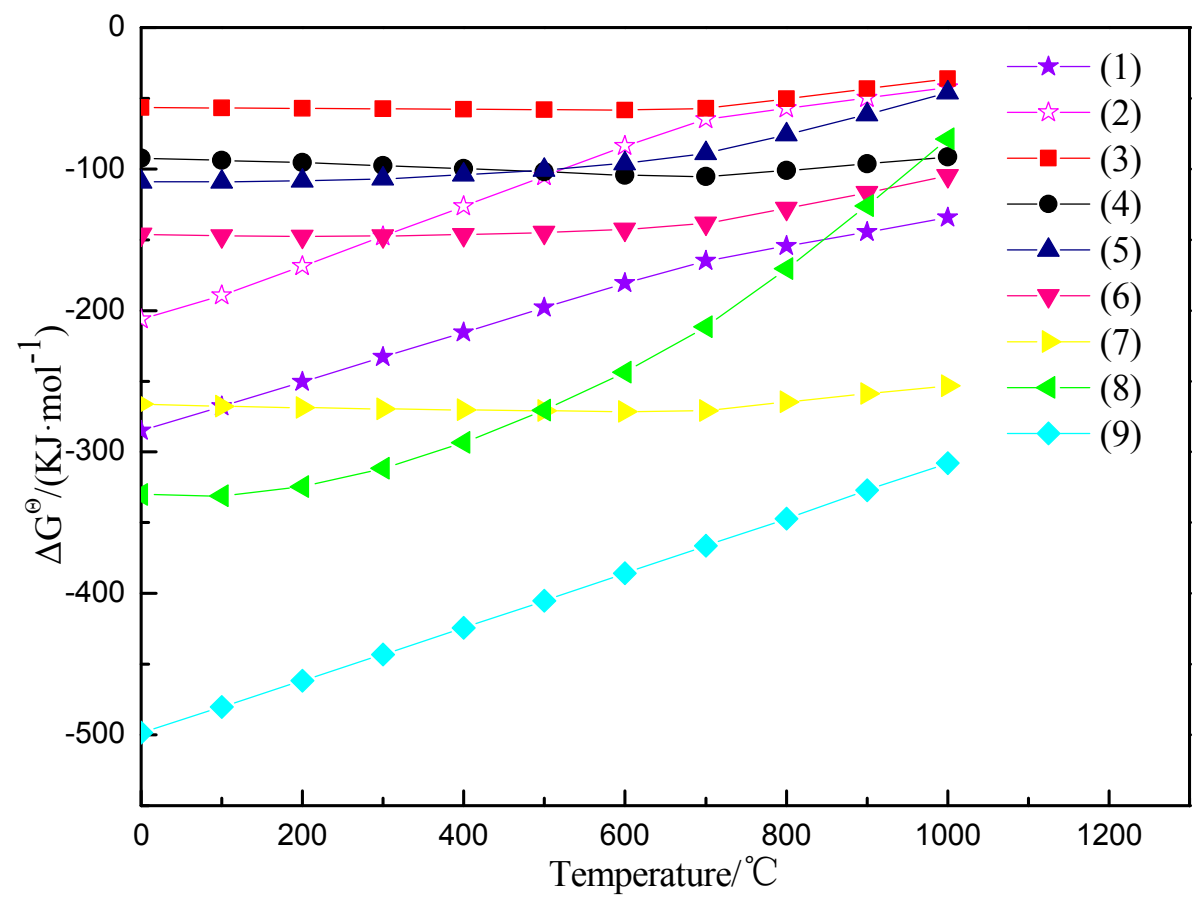

Figure 11. Standard Gibbs free energy changes for main chemical reaction at different temperatures during the stone coal roasting process.

As presented in Figure 11, the standard Gibbs free energy changes $\Delta \mathrm{G}^{\Theta}$ for all of the main chemical reactions were negative over the temperature range of $100-1000{ }^{\circ} \mathrm{C}$, which indicated that the formation of various vanadate compounds and tremolite, and the oxidation of vanadium, were thermodynamically feasible. $\Delta G^{\Theta}$ values for reactions (1) and (2) were negative, indicating that $V(I I I)$ and $\mathrm{V}(\mathrm{IV})$ could be oxidized to $\mathrm{V}(\mathrm{V})$ during the stone coal roasting process, and $\mathrm{V}_{2} \mathrm{O}_{5}$ would react with other oxides to form vanadate.

$\Delta G^{\Theta}$ values for reactions (6)-(8) were more negative than those for reactions (3)-(5) and this meant that the formation of calcium vanadate was easier than that of magnesium vanadate when enough calcium oxide was present. Based on $[29,33,34]$, below $500{ }^{\circ} \mathrm{C}$ the degree of calcite decomposition was low. Due to the deficiency of calcium oxide, magnesium vanadate was more easily formed at temperatures lower than $500^{\circ} \mathrm{C}$. Moreover, the solubility of magnesium vanadate was relatively large. Thus, the vanadium leaching efficiency was enhanced by using $\mathrm{MgO}$ as roasting additive. 
$\Delta \mathrm{G}^{\Theta}$ value for reaction (9) was the most negative, which indicated that in the presence of calcium oxide this reaction was the easiest to happen. When the roasting temperature was higher than $500{ }^{\circ} \mathrm{C}$, calcium oxide produced from the decomposition of calcite increased gradually with the increase of temperature. However, due to the introduction of $\mathrm{MgO}$ during stone coal roasting process, tremolite appeared at high temperature. The formation of tremolite would consume calcium oxide and, thus, the formation of calcium vanadate was hindered. As a result, $\mathrm{V}_{2} \mathrm{O}_{5}$ would react with $\mathrm{MgO}$ to form magnesium vanadate. Accordingly, the vanadium leaching efficiency of roasting with $\mathrm{MgO}$ was higher than that of blank roasting at high temperature.

\section{Conclusions}

In this study, vanadium was extracted from stone coal by roasting with $\mathrm{MgO}$ and leaching with sulfuric acid, and the function of $\mathrm{MgO}$ during stone coal roasting process was analyzed. The following conclusions can be drawn:

(1) The vanadium leaching efficiency of $86.63 \%$ was obtained under the experimental conditions that the particle size of raw ore was $\sim 0.074 \mathrm{~mm}$ accounting for $75 \%$, the roasting temperature was $500{ }^{\circ} \mathrm{C}$, the roasting time was $1 \mathrm{~h}$, the $\mathrm{MgO}$ addition was $3 \mathrm{wt} \%$, the sulfuric acid concentration was $20 \mathrm{vol} \%$, the liquid-to-solid ratio was $1.5 \mathrm{~mL} / \mathrm{g}$, the leaching temperature was $95^{\circ} \mathrm{C}$, and leaching time was $2 \mathrm{~h}$. However, under the same conditions only $78.90 \%$ of vanadium was leached during blanking roasting and the sulfuric acid leaching process. Thus, the vanadium leaching efficiency increased by $7.73 \%$ by using $\mathrm{MgO}$ as the roasting additive.

(2) During the roasting process the formation of calcium vanadate was easier than that of magnesium vanadate when enough calcium oxide was present. Below $500{ }^{\circ} \mathrm{C}$ the degree of calcite decomposition was low. Due to the deficiency of calcium oxide which was produced from the decomposition of calcite, magnesium vanadate was more easily formed. Moreover, magnesium vanadate was easier to be dissolved than calcium vanadate during the sulfuric acid leaching process. Hence, the vanadium leaching efficiency was improved by using $\mathrm{MgO}$ as roasting additive below $500{ }^{\circ} \mathrm{C}$. Additionally, tremolite appeared at high temperature, which would consume calcium oxide produced from the decomposition of calcite. As a result, the formation of calcium vanadate was hindered and $\mathrm{V}_{2} \mathrm{O}_{5}$ would react with $\mathrm{MgO}$ to form magnesium vanadate. Accordingly, the vanadium leaching efficiency of roasting with $\mathrm{MgO}$ was higher than that of blank roasting at high temperature.

Acknowledgments: This work was supported by the Project of National Natural Science Foundation of China (No. 51474162 \& No. 51404174) and the Key Science and Technology Support Program (No. 2015BAB18B01) from the Ministry of Science and Technology of China.

Author Contributions: Fang Chen and Yimin Zhang conceived and designed the experiments; Fang Chen performed the experiments; Fang Chen and Nannan Xue analyzed the data; Yimin Zhang, Jing Huang contributed reagents/materials/analysis tools; and Fang Chen wrote the paper.

Conflicts of Interest: The authors declare no conflict of interest.

\section{References}

1. Skyllaskazacos, M.; Cao, L.Y.; Kazacos, M.; Kausar, N.; Mousa, A. Vanadium electrolyte studies for the vanadium redox battery-A review. ChemInform 2016, 47, 1521-1543. [CrossRef]

2. Aureliano, M. Decavanadate Toxicology and Pharmacological Activities: $\mathrm{V}_{10}$ or $\mathrm{V}_{1}$, Both or None? Oxid. Med. Cell. Longev. 2016, 2016, 6103457. [CrossRef] [PubMed]

3. Yang, X.; Zhang, Y.M.; Bao, S.X. Separation and recovery of sulfuric acid from acidic vanadium leaching solution of stone coal via solvent extraction. J. Environ. Chem. Eng. 2016, 4, 1399-1405. [CrossRef]

4. Bin, Z.Y. Progress of the research on extraction of vanadium pentoxide from stone coal and the market of the $\mathrm{V}_{2} \mathrm{O}_{5}$. Hunan Nonferr. Met. 2006, 22, 16-20.

5. Shang, G.H.; Zhang, G.Q.; Gao, C.J.; Fu, W.; Zeng, L. A novel nanofiltration process for the recovery of vanadium from acid leach solution. Hydrometallurgy 2013, 142, 94-97. [CrossRef] 
6. Xue, N.N.; Zhang, Y.M.; Liu, T.; Huang, J.; Liu, H.; Chen, F. Mechanism of vanadium extraction from stone coal via hydrating and hardening of anhydrous calcium sulfate. Hydrometallurgy 2016, 166, 48-56. [CrossRef]

7. Ye, G.H.; Zhang, S.; He, W.; Tong, X.; Wu, N. Process mineralogy characteristics of stone coal and its relationship to vanadium extraction. Chin. J. Rare Met. 2014, 38, 146-157.

8. Hu, P.C.; Zhang, Y.M.; Liu, T.; Huang, J.; Yuan, Y.Z.; Zheng, Q.S. Highly selective separation of vanadium over iron from stone coal by oxalic acid leaching. J. Ind. Eng. Chem. 2016, 45, 241-247. [CrossRef]

9. Wang, F.; Zhang, Y.M.; Liu, T.; Huang, J.; Zhao, J.; Zhang, G.B.; Liu, J. Comparison of direct acid leaching process and blank roasting acid leaching process in extracting vanadium from stone coal. Int. J. Miner. Process. 2014, 128, 40-47. [CrossRef]

10. Xue, N.N.; Zhang, Y.M.; Liu, T.; Huang, J. Study of the dissolution behavior of muscovite in stone coal by oxygen pressure acid leaching. Metall. Mater. Trans. B 2016, 47, 694-701. [CrossRef]

11. Wang, M.Y.; Wang, X.W. Research status and prospect of vanadium leaching processes from stone coal. Chin. J. Rare Met. 2010, 34, 90-97.

12. Wang, M.Y.; Xian, P.F.; Wang, X.W.; Li, B.W. Extraction of vanadium from stone coal by microwave assisted sulfation roasting. JOM 2015, 67, 369-374. [CrossRef]

13. He, D.S.; Feng, Q.M.; Zhang, G.F.; Ou, L.M.; Lu, Y.P. An environmentally-friendly technology of vanadium extraction from stone coal. Miner. Eng. 2007, 20, 1184-1186. [CrossRef]

14. Deng, Z.G.; Wei, C.; Fan, G.; Li, M.T.; Li, C.X.; Li, X.B. Extracting vanadium from stone-coal by oxygen pressure acid leaching and solvent extraction. Trans. Nonferr. Met. Soc. China 2010, 20, S118-S122. [CrossRef]

15. Wang, T.Y.; Xu, L.J.; Liu, C.L.; Zhang, Z.D. Calcified roasting-acid leaching process of vanadium from low-grade vanadium-containing stone coal. Acta Geochim. 2014, 33, 163-167. [CrossRef]

16. Zhang, X.G.; Gao, Y.B.; Xu, Q.; Liu, D.J.; Long, H.; Tang, Y. Vanadium anhydride extracted from stone coal by calcified roasting and $\mathrm{NaOH}$ leaching. Appl. Chem. Ind. 2013, 42, 1026-1028.

17. Zeng, Y.Y.; Hua, J.; Yan, W.B.; Gao, F.; Cai, J. Leaching vanadium and silicon from stone coal by alkaline process. J. Jishou Univ. Nat. Sci. Ed. 2015, 36, 59-62.

18. Jin, X.J.; Yang, C.P.; Zeng, G.M.; He, H.J.; Li, C.L.; Luo, Z.B.; Luo, S.X. Vanadium extraction technology from stone coal by oxidizing roasting-alkaline leaching method. Chin. J. Nonferr. Met. 2014, 24, 3177-3184.

19. Wang, P.; Feng, Y.L.; Li, H.R.; Zhang, P.; Liu, X.W. Extracting vanadium from high-carbon stone coal by oxidizing roasting-acid leaching method. J. Cent. South Univ. (Sci. Technol.) 2011, 42, 2917-2921.

20. Zhao, Q.; Ning, S.M.; She, Z.H.; Huang, Z.G. Extracting vanadium from stone coal with composite additive. Chin. J. Rare Met. 2013, 37, 961-967.

21. Cai, Z.L.; Zhang, Y.M.; Liu, T.; Huang, J. Mechanisms of vanadium recovery from stone coal by novel $\mathrm{BaCO}_{3} / \mathrm{CaO}$ composite additive roasting and acid leaching technology. Minerals 2016, 6, 26-39. [CrossRef]

22. Wang, F.; Zhang, Y.M.; Liu, T.; Huang, J.; Zhao, J.; Zhang, G.B.; Liu, J. A mechanism of calcium fluoride-enhanced vanadium leaching from stone coal. Int. J. Miner. Process. 2015, 145, 87-93. [CrossRef]

23. Hu, Y.J.; Zhang, Y.M.; Bao, S.X.; Liu, T. Effects of the mineral phase and valence of vanadium on vanadium extraction from stone coal. Int. J. Miner. Metall. Mater. 2012, 19, 893-898. [CrossRef]

24. Lu, M.; Zhang, Y.M.; Liu, T.; Yang, D. Sintering action of $\mathrm{NaCl}$ calcination during extracting vanadium from stone coal. Chin. J. Rare Met. 2009, 33, 894-897.

25. Zhu, X.B.; Zhang, Y.M.; Liu, T. Experiment and Mechanism of Vanadium Extraction from Stone Coal by Roasting with Activators. Chin. J. Rare Met. 2013, 37, 283-288.

26. Joung, M.R.; Kim, J.S.; Song, M.E.; Nahm, S.; Paik, J.H. Formation and microwave dielectric properties of the $\mathrm{Mg}_{2} \mathrm{~V}_{2} \mathrm{O}_{7}$ ceramics. J. Am. Ceram. Soc. 2009, 92, 3092-3094. [CrossRef]

27. Zubkov, V.G.; Leonidov, I.A.; Poeppelmeier, K.R.; Kozhevnikov, V.L. Subsolidus-phase equilibria in the system $\mathrm{MgO}-\mathrm{V}_{2} \mathrm{O}_{5}-\mathrm{MoO}_{3}$. J. Solid State Chem. 1994, 111, 197-201. [CrossRef]

28. Ji, C.L.; Zhan, Q.L.; Zeng, G.Y. Solubility of magnesium vanadates in water-A basic study on extraction of vanadium from iron ore concentrate pellets with non-sodium salt additive. Nonferr. Met. 1984, 36, 60-66.

29. He, D.S. Theoretical Investigation of Roasting and Leaching Process of Stone Coal-Type Vanadium Ore. Ph.D. Thesis, Central South University, Changsha, China, 2009.

30. Ronie, A. Outokumpu HSC Chemistry for Windows: Chemical Reaction and Equilibrium Software with Extensive Thermochemical Database; Outokumpu Research OY: Pori, Finland, 2006.

31. Li, W.B.; Yuan, Z.F.; Liu, J.X.; Xu, C.; Wei, Q.S. Thermodynamics on the carbochlorination of titanium-bearing ores. Chin. J. Process Eng. 2004, 4, 121-123. 
32. Wang, Y.K. Application of HSC chemistry software in university chemical scientific research. J. Henan Inst. Educ. 2013, 22, 28-30.

33. Wang, Y.; Thomson, W.J. The effects of steam and carbon dioxide on calcite decomposition using dynamic X-ray diffraction. Chem. Eng. Sci. 1995, 50, 1373-1382. [CrossRef]

34. Spinolo, G.; Anselmi-Tamburini, U. Mechanism of low temperature calcite decomposition. Solid State Ion. 1989, 32, 413-419. [CrossRef]

(c) 2017 by the authors. Licensee MDPI, Basel, Switzerland. This article is an open access article distributed under the terms and conditions of the Creative Commons Attribution (CC BY) license (http://creativecommons.org/licenses/by/4.0/). 